\title{
Use of an Additional Diagnostic Work-up Following a Treatment Recommendation from the Preoperative Conference of the Mammography Screening Units
}

\author{
Nutzen einer zusätzlichen Diagnostik nach bereits erfolgter Therapieempfehlung \\ aus den präoperativen Konferenzen der Mammografie-Screening-Einheiten
}

Authors

Affiliations
K.-J. Winzer ${ }^{1}$, S. Unger ${ }^{1}$, U. Bick ${ }^{2}$, F. Dieckmann ${ }^{3}$, E. Fallenberg ${ }^{4}$

1 Department of Gynecology and Gynecologic Oncology, Charité Campus Mitte, Charité-Universitätsmedizin Berlin, Berlin

${ }^{2}$ Institute of Radiology, Charité Campus Mitte, Charité-Universitätsmedizin Berlin, Berlin

${ }^{3}$ Institut für Radiologische Diagnostik, St. Joseph-Stift Bremen, Bremen

${ }^{4}$ Department of Nuclear Medicine, Charité Campus Virchow-Klinikum, Charité-Universitätsmedizin Berlin, Berlin

\section{Key words}

- mammary carcinoma

- mammography screening

- ultrasound

Schlüsselwörter

- Mammakarzinom

- Mammografie-Screening

- Ultraschall

Deutschsprachige

Zusatzinformationen online abrufbar unter: www.thieme-connect.de/ ejournals/toc/gebfra

received $\quad 5.2 .2013$

revised 25.12.2013

accepted $\quad 31.12 .2013$

\section{Bibliography}

Dol http://dx.doi.org/

10.1055/s-0033-1360322

Geburtsh Frauenheilk 2014; 74: 370-375 @ Georg Thieme

Verlag KG Stuttgart - New York . ISSN 0016-5751

\section{Correspondence}

Dr. Klaus-Jürgen Winzer

Charité - University Medicine Berlin

Breast Centre

Charité-Platz 1

10117 Berlin

klaus-juergen.winzer@

charite.de

\section{Abstract}

$\nabla$

Objective: If a focus of suspicion is classified as being B 3-5 by a punch biopsy as part of a mammography screening, a recommendation for further action to be taken will be given in the preoperative conference of the screening unit. As part of this investigation, these treatment recommendations were compared with the final therapeutic approach taken at a certified breast centre. Furthermore, it was investigated whether and which additional examinations were performed on patients, depending on compliance with the recommended treatment.

Material and Method: The data from 272 breast cancer patients from the years 2007, 2008 and 2009 was analysed. The patients took part in the screening programmes of four screening units in the German mammography screening programme, in one federal state. In addition, the data from each patient from one screening unit was analysed in two further federal states.

Results: In total, the most recently conducted intervention deviated from the treatment recommendation from the preoperative conference in the screening unit in 77 out of 272 patients (28.3\%). Of these, there were 50 recommendations for open biopsy which ultimately resulted in breast-conserving surgery, which is not to be evaluated as an error, as the bioptic result was supplemented by the open biopsy. Additional examinations were performed in patients with deviating treatment recommendation in 39 cases (50.6\%) and in patients without deviating treatment recommendation in 66 cases (34.0\%). The additional examinations carried out included additional punch biopsies (most frequent) and MRI scans, but also additional ultrasounds or a mammography.

Conclusions: Additional examinations lead to a change in treatment in a higher percentage of patients in comparison with the initial screening in-

\section{Zusammenfassung \\ $\nabla$}

Ziel: Wird im Rahmen des Mammografie-Screenings ein verdächtiger Herd durch eine Stanzbiopsie nach B 3-5 klassifiziert, so wird in der präoperativen Konferenz der Screening-Einheit eine Empfehlung zum weiteren Vorgehen gegeben. Im Rahmen dieser Untersuchung wurden diese Therapieempfehlungen mit dem endgültigen therapeutischen Vorgehen an einem zertifizierten Brustzentrum verglichen. Weiterhin wurde untersucht, ob und welche Zusatzuntersuchungen bei den Patientinnen in Abhängigkeit von der Einhaltung der Therapieempfehlung durchgeführt wurden.

Material und Methode: Analysiert wurden die Daten von 272 Mammakarzinompatientinnen aus den Jahren 2007, 2008 und 2009. Die Patientinnen nahmen am Screening-Programm vierer Screening-Einheiten eines Bundeslandes des deutschen Mammografie-Screening-Programms teil. Zudem wurden die Daten je einer Patientin aus einer Screening-Einheit zweier weiterer Bundesländer analysiert.

Ergebnisse: Insgesamt weicht der letztlich durchgeführte Eingriff von der Therapieempfehlung aus der präoperativen Konferenz in der Screening-Einheit bei 77 von 272 Patientinnen (28,3\%) ab. Darunter befinden sich aber 50 Empfehlungen zur offenen Biopsie, die letztlich eine BET ergaben, was nicht als Fehler zu werten ist, da das bioptische Ergebnis durch die offene Biopsie bewusst ergänzt wurde. Zusatzuntersuchungen wurden bei Patientinnen mit abweichender Therapieempfehlung in 39 Fällen (50,6\%) durchgeführt, während es bei Patientinnen ohne abweichende Therapieempfehlung 66 (34,0\%) Fälle waren. $\mathrm{Zu}$ den Zusatzuntersuchungen zählten wir die erneute Stanzbiopsie (am häufigsten) und die MRT, aber auch einen erneuten US oder eine Mammografie. 
cluding assessment. An exact reexamination of the findings obtained in the screening is therefore preoperatively necessary in order to guarantee optimum treatment.
Schlussfolgerungen: Zusatzuntersuchungen führen im Vergleich zum initialen Screening incl. Assessment bei einem höheren Prozentsatz der Patientinnen zu einer Therapieänderung. Eine exakte Aufarbeitung der im Screening erhobenen Befunde ist daher präoperativ notwendig, um eine optimale Therapie zu gewährleisten.

\section{Introduction}

$\nabla$

Germany's comprehensive mammography screening, based on the "European guidelines for quality assurance in breast cancer screening and diagnosis", [1] was agreed by the German Parliament in 2002 and was introduced step-by-step, beginning in May 2005. The introduction of comprehensive screening was completed in 2008.

All women without clinical symptoms aged between 50 and 69 were invited to take part in digital mammographies two years apart, whereby a standard second examination was subsequently carried out. The complete participation of all eligible women was not achieved for various reasons. A clinical examination or additional mammography is not provided by the screening programme.

In the case of abnormalities in the mammography, patients are invited for additional examinations in the form of special imaging (enlarged images, spot images focussed on a densification or additional projections) or to an ultrasound scan. If clinical suspicion of a malignant tumour arises from the routine imaging as well as the additional examinations [2], the screening unit will initiate a histological analysis through a minimally invasive punch biopsy or vacuum-assisted biopsy. Only in very rare cases, e.g. in the case of anatomical peculiarities (very small breast, calcifications close to the breast wall or in an axillary position), for which a minimally invasive biopsy is technically impossible, is an open biopsy required. The result of this histopathological examination is checked for its correlation with the diagnosis given by the imaging in a multidisciplinary conference of X-ray-screening diagnosticians, pathologists, surgeons and the partial inclusion of the treating gynaecologists. In the case of unconformity between abnormalities suspected to be malignant in the imaging diagnostic procedures and benign histological findings that cannot be explained by the structure of these benign findings, a re-biopsy or early check will take place [3].

Should an invasive carcinoma, a ductal carcinoma in situ (B5 lesion) or a B3 or B4 lesion (lesion with unclear malignant potential or suspected presence of a carcinoma) appear histologically, the patient will be transferred to a certified breast centre for further treatment.

An assessment is therefore generally carried out as part of the mammography screening, even when an additional focus is detected by the imaging or has not yet been clarified histologically. Recommendations for further treatment and diagnosis are given in the multidisciplinary conference.

The results and recommendations are documented in certified software ('Mammasoft' or 'MaSc').

Structured quality assurance takes place in the postoperative conference regarding serious deviations in the size and type of tumour preoperatively and postoperatively, as well as through the detection of interval carcinomas. The most recently performed operation is also documented in conjunction with the initial recommendations, but the precise reasons for a deviation are not considered.
It is therefore unclear as to whether these differences occur as a result of the findings of the screening examinations and further assessment not being observable, or whether a change in the surgical methods resulted from additional preoperative examinations in the breast centres and the new knowledge regarding the extent or additional malignant findings obtained therefrom.

Whether postoperative or histological findings from imaging that lead to a surgical extension were the cause is also not considered. The goal of the analysis was therefore to investigate the influence of further preoperative examinations and interventions in the breast centres indicated on the procedures suggested by the screening units, regardless of the screening results.

These additional examinations in the breast centres are not provided for in the federal master agreement for the training programme.

\section{Material and Method \\ $\nabla$}

All 272 patients that came to our breast centre from screening units for further operative clarification between May 2007 and December 2009 were analysed retrospectively.

190 patients came from the primary cooperating screening unit. The patients analysed also participated in the screening programmes of three further screening units in the same federal state (53, 21 and 6 patients from each respectively). In addition, each patient's data from two further screening units was analysed with respect to the initial recommendation of the multidisciplinary conference and the ultimate procedure. The data was taken from the screening units' written documentation in the respective, certified documentation software as well as the patient files and findings reports in our breast centre.

\section{B categories and recommended procedure}

The distribution of the $\mathrm{B}$ categories and the recommended type of operation for the individual patients was analysed and the type of operation planned was compared with the operation that was eventually performed as well as the histological results before and after the operation.

\section{Additional examinations and their effects}

The treatment recommendations as well as the number and type of further, non-operative recommendations entered under the "Other" heading were also extracted from the "Mammasoft" screening software.

These further recommendations under the "Other" sub-category in the software are occasionally documented in more detail in an additional free-text field.

Although the B3 lesions were not included in the actual assessment, they were included in the overview ( $\nabla$ Table 1 ) between the biopsy results and the final result in order to illustrate the potential number of false positive B4 lesions. This case resulted from the uncertainty evident in the description, but which led to B4 classification. 
Table 1 B classification biopsy cross-table * B-equivalent classification postoperatively.

\begin{tabular}{|c|c|c|c|c|}
\hline \multirow[t]{2}{*}{ B classification } & \multicolumn{3}{|c|}{ B-equivalent classification postoperatively } & \multirow[t]{2}{*}{ Total } \\
\hline & $\begin{array}{l}\text { Benign, but with uncertain } \\
\text { biological potential }\end{array}$ & $\begin{array}{l}\text { Non-invasive mam- } \\
\text { mary carcinoma }\end{array}$ & $\begin{array}{l}\text { Invasive mammary } \\
\text { carcinoma }\end{array}$ & \\
\hline B3 - benign, but with uncertain biological potential & 44 & 3 & 1 & 48 \\
\hline B4 - suspected malignancy & 1 & 4 & 1 & 9 \\
\hline B5a - non-invasive mammary carcinoma & 0 & 35 & 12 & 47 \\
\hline B5b - invasive mammary carcinoma & 0 & 1 & 158 & 159 \\
\hline B5c - Disputably invasive mammary carcinoma & 0 & 4 & 0 & 4 \\
\hline No punch biopsy & 2 & 0 & 3 & 5 \\
\hline Total & 47 & 47 & 178 & 272 \\
\hline
\end{tabular}

The preoperative and postoperative tumour sizes were determined and, in addition, the differences between the tumour sizes determined initially and the final histological size were calculated and sorted into three groups of $>+10 \mathrm{~mm},-10 \mathrm{~mm}$ to $+10 \mathrm{~mm}$ and $<-10 \mathrm{~mm}$.

The results of the lymph node staging were analysed.

In addition, the number of operations carried out per patient was determined.

\section{Results}

$\nabla$

The median patient age was 63 (50-70) years old.

The results of the primary assessments of the patients detailed are presented in $\bullet$ Table $\mathbf{2}$.

In total, 219 out of these 272 patients were classified as B4 or B5. In 204 of these patients, a surgical procedure was directly recommended and further diagnostic measures were proposed for the other 15.

\section{B categories and recommended procedure}

A B3 lesion was diagnosed in 48 patients and an open biopsy was recommended. Four $(8.3 \%)$ of these patients then had a malignant tumour in the following histology, meaning that an additional breast-conserving operation was ultimately necessary. Of the five cases in which no punch biopsy could be carried out in the assessment and an open biopsy was then performed, three cases displayed an invasive carcinoma and so also required a further therapeutic operation. The findings for two of these patients were benign.

Lymph node metastasis was displayed in a total of 44 patients (pN1a: $35=12.9 \% /$ pN2a: $6=2.2 \% / p N 3 a: 3=1.1 \%$ ).

Through the primary and necessary re-operations as well as repeat operations due to $\mathrm{R} 1$ resections or two-stage axillary removals, a total of 306 operations were performed (Table 3).

In as early as the screening stage, $28(10.3 \%)$ out of the 272 cases had multi-focal abnormalities and 8 (2.9\%) had bilateral abnormalities, whereby only the most biologically severe side had an influence on further evaluations for the latter group.

In eight cases (2.9\%), for which the screening units deemed both sides to be worth clarifying, bilateral clarification was finally achieved in nine cases (3.3\%), partly through supplementary examinations in the breast centre.

The further evaluations exclusively concerned the 219 B4 and B5 cases.

- Tables $\mathbf{4}$ and $\mathbf{5}$ show the relationship between operations that were planned and operations that were performed. In $82.2 \%$ of cases $(n=180)$, there was conformity between those planned
Table 2 B classification from the screening unit.

\begin{tabular}{|c|c|c|c|}
\hline \multicolumn{2}{|c|}{ B classification } & \multirow{2}{*}{$\begin{array}{l}\mathbf{n}_{48}\end{array}$} & \multirow{2}{*}{$\begin{array}{l}\% \\
17.6\end{array}$} \\
\hline B3 & $\begin{array}{l}\text { Benign, but with uncertain biological } \\
\text { potential }\end{array}$ & & \\
\hline B4 & Suspected malignancy & 9 & 3.3 \\
\hline B5a & Non-invasive mammary carcinoma & 47 & 17.3 \\
\hline B5b & Invasive mammary carcinoma & 159 & 58.5 \\
\hline B5c & Disputably invasive mammary carcinoma & 4 & 1.5 \\
\hline \multicolumn{2}{|c|}{ No punch biopsy } & 5 & 1.8 \\
\hline \multicolumn{2}{|c|}{ Total } & 272 & 100.0 \\
\hline
\end{tabular}

Table 3 Number of surgical interventions per patient.

\begin{tabular}{|lrr|}
\hline Number & $\mathbf{n}$ & \% \\
1 & 240 & 88.2 \\
\hline 2 & 30 & 11.0 \\
\hline 3 & 2 & 0.7 \\
\hline Total & 272 & 100.0 \\
\hline
\end{tabular}

and those performed, and $11.0 \%(n=24)$ displayed a deviation. Thereby, there was low total conformity with a Kappa of 0.294 [3]. The test as to whether Kappa $=0$ (full conformity) was rejected with a significance of 0.000 .

There was no assertion in 15 cases, as "other" had been entered into the Mammasoft software and therefore further clarification was recommended instead of surgical treatment.

\section{Additional examinations and their effects}

Documented under "Other", the screening unit suggested an additional MRI on four occasions, an additional punch biopsy on three occasions and eight open biopsies. In total, an additional three ipsilateral and one contralateral ultrasounds, five ipsilateral mammographies as well as seven ipsilateral punch biopsies were performed on these patients.

Among the deviations due to additional examinations carried out with further suspect findings detected as a result, presented in - Table 6, was a change in size ( Table 7) that made an expanded operation necessary, or also allowed for a smaller operation, and serious histopathological results ( Table 8).

Additional examinations were conducted as a result of clinically occult findings that were detected while preparing for the operation or during marking or following the upgrade of the lesion in the histology and the therefore further indication for assessment 
Table 4 Cross-table of planned surgical screening * operation performed.

\begin{tabular}{|c|c|c|c|c|c|c|}
\hline \multirow{3}{*}{$\begin{array}{l}\text { Planned } \\
\text { operation }\end{array}$} & \multirow[b]{3}{*}{ Preoperative MRI scan } & & \multicolumn{3}{|c|}{ Operation performed } & \multirow[t]{2}{*}{ Total } \\
\hline & & & $\begin{array}{l}\text { Breast-conserving } \\
\text { surgery }\end{array}$ & Mastectomy & $\begin{array}{l}\text { Secondary } \\
\text { mastectomy }\end{array}$ & \\
\hline & & $\begin{array}{l}\text { "Other" in } \\
\text { Mammasoft }\end{array}$ & 4 & 0 & 0 & 4 \\
\hline & Preoperative 2 nd focus punching & & 3 & 0 & 0 & 3 \\
\hline & Open biopsy & & 8 & 0 & 0 & 8 \\
\hline & Breast-conserving surgery & & 169 & 13 & 8 & 190 \\
\hline & Mastectomy & & 3 & 11 & 0 & 14 \\
\hline Total & & & 187 & 24 & 8 & 219 \\
\hline
\end{tabular}

Table 5 Symmetrical measurements.

\begin{tabular}{|c|c|c|c|c|}
\hline & Value & $\begin{array}{l}\text { Asymptotic } \\
\text { standard error }^{\mathrm{a}}\end{array}$ & Approximate $\mathrm{T}^{\mathrm{b}}$ & $\begin{array}{l}\text { Approximate } \\
\text { significance }\end{array}$ \\
\hline Extent of conformity (Карра) & 0.294 & 0.080 & 6.274 & 0.000 \\
\hline Number of applicable cases & 219 & & & \\
\hline
\end{tabular}

a The null hypothesis was not accepted.

${ }^{\mathrm{b}}$ When assuming the null hypothesis, the asymptotic standard error is used.

Table 6 Cross-table between additional examinations and the comparison of the treatment suggested in the screening unit with the treatment actually provided.

\begin{tabular}{|c|c|c|c|c|c|}
\hline & & \multicolumn{3}{|c|}{ Comparison of treatments } & \multirow[t]{2}{*}{ Tota } \\
\hline & & Conformity & Deviation & $\begin{array}{l}\text { No assertion, } \\
\text { because "other" }\end{array}$ & \\
\hline \multirow[t]{2}{*}{ Additional examination } & Performed & 60 & 16 & 12 & 88 \\
\hline & Not performed & 120 & 8 & 3 & 131 \\
\hline Total & & 180 & 24 & 15 & 219 \\
\hline
\end{tabular}

in the case of lesions that had previously only been regarded as element to control.

The influence of additional examinations on patients for whom no clear treatment recommendation was initially given was considered in detail, showing that 76 additional examinations carried out resulted in a change of treatment in 16 cases, whereas there was a change of treatment in only 8 cases out of 128 when no additional examinations were performed. In total, there was treatment conformity in 180 patients and treatment deviation in 24 patients. No assertion could be made for 15 patients, as there was initially no treatment recommended and "other" was entered ( $\bullet$ Table 6$)$.

For the ratio of conformity versus deviation regarding the initial treatment recommendation, the following pairs arise for the individual additional examinations carried out:

- Ipsilateral ultrasound 9:4,

- contralateral ultrasound $1: 1$,

- ipsilateral mammography $3: 1$,

- contralateral mammography $1: 0$,

- ipsilateral punch biopsy $27: 10$,

- contralateral punch biopsy $1: 0$,

- MRI 35:11.

In addition, one patient in the group with conformity rejected the recommended MRI. Multiple additional examinations were conducted for some patients, which explains the total of additional examinations deviating from the number of patients.

There was a deviating postoperative result with regards to histology in 37 (16.9\%) out of the 219 cases.
Table 7 Difference in $\mathrm{mm}$ of the imaging diagnostics in the screening and histopathological finding.

\begin{tabular}{|lcc|} 
Difference in $\mathbf{~ m m}$ & Frequency & Percentage \\
$\leq-10$ & 29 & 13.2 \\
\hline$>-10<+10$ & 156 & 71.2 \\
\hline$\geq+10$ & 31 & 14.2 \\
\hline None & 3 & 1.4 \\
\hline Total & 219 & 100.0 \\
\hline
\end{tabular}

Here, it is to be noted that some of the descriptive histological assertions were not formulated as unambiguously as when they were finally documented under B classification. Table 8 presents the comparison between the accuracy of the descriptive histology within the groups and the conformity with the original treatment suggestion.

\section{Discussion}

\section{Problem of B lesions}

With this evaluation, the potential extent of further diagnostic measures before the definitive operative treatment outside the screening unit on the recommended treatment should be illuminated.

The reason why these further measures were not carried out before the patients went to the breast centres lies in the organisation of the mammography screening [4-5]. An evaluation of 
Table 8 Cross-table between histopathological diagnosis and the comparison of the treatment suggested in the screening unit and treatment actually given.

\begin{tabular}{|lllll}
\hline Pathology & \multicolumn{2}{c}{ Comparison of Treatments } & \multicolumn{2}{c}{ Total } \\
& Conformity & Deviation & No assertion & 188 \\
\hline Unambiguous histological assertion & 156 & 22 & 10 & 19 \\
\hline “Consistent with” & 14 & 1 & 4 & 219 \\
\hline Different histological differential diagnoses & 10 & 24 & 15 & 219 \\
\hline Total & 180 & 24 & \\
\hline
\end{tabular}

how often additional preoperative diagnostics take place following the completion of the assessment in the screening unit is not known to us and we therefore cannot make a comparison of this here.

In accordance with previous agreements, diagnostic investigation in the context of a mammography screening ends upon the confirmation of a B3-5 lesion and ideally the open biopsy and/or definitive treatment will have taken place in a certified breast centre in accordance with oncological guidelines.

Depending on the existing histological result, the procedure and further consecutive therapeutic measures taken differ in the case of increasingly individualised treatment [6].

The proportion of malignant findings that make a further oncological operation necessary then varies in the case of open biopsies of B3 changes, for example, depending on the percentage of $\mathrm{ADH}$ (atypical ductal hyperplasia) or a potential histological result following the punch biopsy that corresponds to a B3 lesion, as there is only a quantitative difference between $\mathrm{ADH}$ and a low grade DCIS.

This is one reason for the deviation between the recommendation and the eventual treatment provided and the higher number of operations than number of patients.

In our group, this was the case in $8.3 \%$ of our B3 cases, which corresponds to around one third of the number reported by the Weigel et al. working group [7].

Weigel et al. published a B3 lesion rate of $15.1 \%$ of 37178 patients across the German mammography screening and a minimally invasive clarification in 979 of these participants. The presence of B4 lesions was proven in $0.4 \%(n=4)$ of cases, and B5 lesions were evinced in $36.3 \%(n=355)$ of cases. In the case of B3 lesions, for which the recommended surgical excision (91/109) was ultimately carried out, there were 25 malignant findings, which corresponded to a PPV of 0.28 for a malignant finding.

Deviations from the recommended procedure resulted from the patient rejecting the operation or the operation being delayed until the time of the evaluation [7].

$12.5 \%$ B3 lesions $(n=250)$ was reported by the Hannover/ Schaumburg screening unit for the years 2006-2009. Of these, an open biopsy was only carried out in $66.5 \%(n=183)$ of cases. The authors calculated a projected malignancy rate of $16 \%$ for all B3 lesions, although a control imaging examination was only carried out in $33.5 \%$ of cases [8].

This corresponds to roughly double the rates we calculated.

In the case studies we participated in, almost all B3 lesions led to an open biopsy, also taking possible overdiagnosis (quaternary prevention) into consideration. The prevalence of malignant tumours could not be presented as a percentage due to the different breast centres taking part (one screening unit cooperates with multiple breast centres) as well as partly due to us not having data available.

In comparison with the period from 1998 to 2000, a study from Nottingham showed that there had been an increase in B3 lesions from 3.1 to $4.5 \%$ by $2007-2008$, while at the same time the positive predictive value fell from 25 to $10 \%$. There were no significant changes of this kind in the same study for B4 lesions [9]. This evaluation is the view of one surgical facility, which had no influence on whether all or a particular representative percentage of patients with B3 lesions were admitted there from the screening units. It is also not known what percentage of patients with B3 lesions were recommended an open biopsy by their respective screening units in its evaluation. The B3 lesions were therefore addressed in detail.

\section{Upgrade from punch biopsy to definitive histology}

This investigation-related diagnostic uncertainty with regards to B3 lesions due to the biopsies not always being representative, also applies to a limited extent for the DCIS, and in some cases leads to an upgrade in its grading.

In the cases available to us, $6.8 \%$ were upgraded to DCIS and $2.3 \%$ to a carcinoma.

These results correspond to what is commonly experienced with limited diagnostic precision from different biopsy methods [1012]. Kettritz et al., for example, reported an upgrade rate of $24 \%$ from $\mathrm{ADH}$ to DCIS and of $12 \%$ from DCIS to carcinoma following a vacuum-assisted biopsy [13]. However, the upgrade rate in the group of patients available to us turned out to be much lower, and does not lend itself to a one-for-one comparison due to the incomplete data situation (see above). It is a point in support of a more precise biopsy method.

\section{Size deviations and multi-stage operations}

There were more and more differences in the preoperative imaging diagnostics in clinical practice with regard to size, which can ultimately prevent a planned breast-conserving procedure and force a change in treatment, e.g. from a breast-conserving operation to a primary or secondary mastectomy.

From a variety of comparative studies between mammography on its own and magnetic resonance imaging (MRI) of the breast with mammography, it is known that mammography's ability to estimate size alone is limited, particularly with dense gland tissue $[14,15]$.

The studies of preoperative radiology also show that the extension is difficult to estimate, particularly when a lesion possesses an imaging correlate that is visible only to a limited extent. Here, the ability to assess the free edge is limited [16].

The deviation in size is also the main reason for multi-stage operations, as the follow-up resections that constitute part of the multi-stage operations can be explained by this. The further part resulted from the sentinel lymph node biopsies following an upgrade regarding the grading or a positive sentinel lymph node not recognised in the intra-operative quick section which involved an axilla dissection. 


\section{Supplementing the diagnosis through}

\section{additional diagnostic investigation}

What is decisive, however, is the assertion of to what extent additional diagnostic measures lead to further suspect lesions being discovered, and how far this additional diagnostics leads to changed treatment options. The examination presented here does not indicate this for surgery ( $\bullet$ Table 3 ). Changes in systematic treatment resulting therefrom were not recorded. Finally, it must be verified in a long-term analysis whether more diagnostic investigation leads to life being extended. The unclear diagnostic possibilities in the imaging examinations of the mammary do not always lead to changes in the operation decision in the case of additional examinations and potentially further biopsies. Therefore, the subjective costs for the patients compared to the diagnostic gains in the decision for additional investigation steps are to be weighed up against each other.

In accordance with the S3 guidelines, ultrasound is the firstchoice method in curative situations in the case of an unclear mammography finding. An ultrasound was recommended as a supplementary method from the outset for women with an ACR density index of between 3 and 4 . When an ultrasound scan and an MRI were also added to the screening due to the presence of a dense parenchyma, this resulted in a higher false positive rate as well as a higher carcinoma detection rate [17] The comparative study of the American College of Radiology Imaging Network showed that, for women aged forty years and older, almost 30\% more tumours were detected through adding a mammography ultrasound to the screening, but this also leads to false positive diagnoses in almost four times as many cases [18].

The QuaMaDi cohort (open, quality-assured breast diagnostics for all legally insured women in Schleswig-Holstein), who received an additional ultrasound in the case of grade 3 or 4 ACR gland parenchyma thickness, showed that an additional $10 \%$ of cases of breast cancer could be identified through a double reading of the mammographies or an additional ultrasound [19]. This emphasises the necessity for additional examinations for selected patients.

It is also worth discussing whether the potentially necessary additional examinations should still take place in a radiological facility (the screening unit) or be delegated to the breast centres.

\section{Conclusion for Clinical Practice \\ $\nabla$}

A higher percentage of patients who received surgical treatment that deviated from the original treatment recommendation made by the screening units underwent additional examinations than those who did not. This does not mean that as many additional examinations should be carried out as possible, but rather that they should be in the case of ambiguous radiological findings. The surgeon ultimately selected by the patients must be aware of the limits of the screening programme and the therefore sometimes incomplete assessment of a patient's findings, and should thus carry out a preoperative evaluation in close cooperation with the clinical radiologists and order additional examinations if necessary.

\section{Conflict of Interest}

\section{$\nabla$}

None.

\section{References}

1 Perry N, Broeders $M$, de Wolf $C$ et al., eds. European guidelines for quality assurance in breast cancer screening and diagnosis. 4 th ed. Luxembourg: Office for Official Publications of the European Communities; 2006

2 American College of Radiology. Breast Imaging Reporting and Data System: BI-RADS. 4th edition. Reston, VA: American College of Radiology; 2003

3 Heywang-Koebrunner S, Bock K, Heindel W et al. Mammography Screening - as of 2013. Geburtsh Frauenheilk 2013; 73: 1007-1016

4 Landis JR, Koch GG. The measurement of observer agreement for categorical data. Biometrics 1977; 33: 159-174

5 Kamps H. GKV-Mammographie-Screening - System oder Strukturchaos. MedR 2009; 27: 216-221

6 Lux MP, Maass N, Schütz F et al. Breast cancer 2013 - interpretation of new and known data. Geburtsh Frauenheilk 2013; 73: 584-598

7 Weigel S, Decker T, Korsching E et al. Minimal invasive biopsy results of "uncertain malignant potential" in digital mammography screening: high prevalence but also high predictive value for malignancy. Rofo 2011; 183: 743-748

8 Rathmann R, Richter B, Caldarone F et al. B3-Läsionen im Mammographie-Screening - Ergebnisse der Screening-Einheit Hannover/Schaumburg. Conference Compact - 30. Jahrestagung der Deutschen Gesellschaft für Senologie Hamburg, 1.-3. Juli 2010, Seite 5

9 Rakha EA, Ho BC, Naik V et al. Outcome of breast lesions diagnosed as lesion of uncertain malignant potential (B3) or suspicious of malignancy (B4) on needle core biopsy, including detailed review of epithelial atypia. Histopathology 2011; 58: 626-632

10 Kettritz U, Rotter $K$, Schreer I et al. Stereotactic vacuum-assisted breast biopsy in 2874 patients: a multicenter study. Cancer 2004; 100: 245251

11 Won B, Reynolds HE, Lazaridis CL et al. Stereotactic biopsy of ductal carcinoma in situ of the breast using an11-gauge vacuum-assisted device: persistent underestimation of disease. AJR Am J Roentgenol 1999; 173: 227-229

12 Jackman RJ, Burbank F, Parker SH et al. Stereotactic breast biopsy of nonpalpable lesions: determinants of ductal carcinoma in situ underestimation rates. Radiology 2001; 218: 497-502

13 Darling ML, Smith DN, Lester SC et al. Atypical ductal hyperplasia and ductal carcinoma in situ as revealed by

large-core needle breast biopsy: results of surgical excision. AJR Am J Roentgenol 2000; 175: 1341-1346

14 Mann RM, Veltman J, Barentsz JO et al. The value of MRI compared to mammography in the assessment of tumour extent in invasive lobular carcinoma of the breast. Eur J Surg Oncol 2008; 34: 135-142

15 Fasching PA, Heusinger $K$, Loehberg $C R$ et al. Influence of mammographic density on the diagnostic accuracy of tumor size assessment and association with breast cancer tumor characteristics. Eur J Radiol 2006; 60: 398-404

16 Schmachtenberg C, Engelken F, Fischer T et al. Intraoperative specimen radiography in patients with nonpalpable malignant breast lesions. Rofo 2012; 184: 635-642

17 Berg WA, Zhang Z, Lehrer D et al. Detection of breast cancer with addition of annual screening ultrasound or a single screening MRI to mammography in women with elevated breast cancer risk. JAMA 2012; 307: 1394-1404

18 Berg WA, Blume JD, Cormack JB et al. Combined screening with ultrasound and mammography vs. mammography alone in women at elevated risk of breast cancer. JAMA 2008; 299: 2151-2163

19 Katalinic A, Waldmann A. Brustkrebs sicher und früh diagnostiziert fast immer geheilt? Geburtsh Frauenheilk 2012; 72: 278-280 